\title{
DIGITALIZATION OF LEAN LEARNING SIMULATIONS: TEACHING LEAN PRINCIPLES AND LAST PLANNER® SYSTEM
}

\author{
Diego Cisterna ${ }^{1}$, Mariana Hergl ${ }^{2}$, Svenja Oprach ${ }^{3}$, and Shervin Haghsheno ${ }^{4}$
}

\begin{abstract}
Lean simulations are an effective way to learn Lean principles and experience the impact on process optimization. However, to date, in construction these have mostly been conducted physically on site or in the office. As digital solutions for collaboration and teaching are increasingly developed in the context of the COVID-19 pandemic, Lean simulations also need to evolve by being decentralized from the project team and driven by digitalization.

This paper examines the adaptation and creation of Lean simulations that can be run on a digital platform that supports interactions between multiple participants in real time. Specifically, two simulations were created through a three-phase iterative development. The first simulation focuses on Lean principles and the second on the Last Planner® System. To evaluate the developed digital simulations, feedback was collected from the participants through questionnaires. It can be noted that all rating results were in the upper range. Research objectives were achieved: The evaluation of the technology, the fun and the design indicate that the participants can successfully interact with each other via the chosen digital platform. It also proved that digital simulations offer high flexibility, integration of technology with low costs and effort as well as a high level of sustainability.
\end{abstract}

\section{KEYWORDS}

Lean principles, Last Planner® System, digital lean simulation, collaboration, action learning.

\section{INTRODUCTION}

Since the fundamental principles of the Toyota Production System were adapted to the construction industry, the application of methods and tools within the emerging field of Lean Construction has proven to be effective in increasing customer value and decreasing waste. Nevertheless, a successful implementation of Lean depends not only on the

1 Research Fellow. Karlsruhe Institute of Technology (KIT), Institute of Technology and Management in Construction, 76131 Karlsruhe, Germany. Phone +49 (0)721 608 45476, diego.cisterna@kit.edu, orcid.org/0000-0003-4282-1141

2 MSc. Industrial Engineering. Karlsruhe Institute of Technology (KIT), Department of Economics and Management, 76133 Karlsruhe, Germany. Phone +49 (0)173 974 5642, mariana.hergl@ t-online.de.

3 Research Fellow. Karlsruhe Institute of Technology (KIT), Institute of Technology and Management in Construction, 76131 Karlsruhe, Germany. Phone +49 (0)721 608 41513, svenja.oprach@ kit.edu, orcid.org/0000-0002-0376-1791

4 Professor. Karlsruhe Institute of Technology (KIT), Institute of Technology and Management in Construction, 76131 Karlsruhe, Germany. Phone +49 (0)721 608 42646, shervin.haghsheno@kit.edu, orcid.org/0000-0002-0602-6370 
understanding of the individual principles, but also on the step-by-step introduction of the whole system philosophy (Liker 2004).

In addition to understanding the technical aspects of the methods; values, behaviours, and the development of social competence - such as team cooperation and interdisciplinary understanding - should be introduced. Teaching methods of the traditional educational system are criticized for neglecting these aspects, since they focus mainly on individual competence. Experts argue that theory alone is not enough to learn Lean Principles and gain understanding for its practical application. Therefore, experiential learning is recommended. (Kriz 2003)

Combining theory with simulations (Herrera et al. 2019) or a systematic approach that both teaches and trains Lean Principles is a good way to reach this objective (CerveróRomero 2013; Heyl 2015). As Rybkowski et al. (2008) states: "Lean simulation games offer educational benefits that cannot be found in textbooks". To date, Lean simulations have been conducted mostly physically on site or in the office: simulations of roads construction (Heyl 2015), aircrafts production (Rybkowki et al. 2008) or the construction of buildings made with Lego® bricks are some examples of this (Dallasega et al. 2020, Gonzalez et al. 2014). As digital solutions for collaboration and teaching are increasingly developed in the context of the COVID-19 pandemic, Lean simulations also need to evolve by being decentralized from the project team and to be used as an innovative teaching tool (Gadre et al. 2011, Dallasega et al. 2020).

Digital simulations are performed on digital devices, where the environment is represented virtually, players interact with virtual elements rather than with real or tangible objects as in physical simulations (Carvalho et al. 2014). And as AbbasianHosseini affirms "computer simulation provides an excellent environment to implement Lean principles, study their effects, and gain a better understanding of how these principles perform." (Abbasian-Hosseini et al. 2014)

By digitalizing the simulations, two important gains are achieved compared to faceto-face simulations: (1) It eliminates the need to allocate all participants in the same place and can even allow interaction between participants from several countries around the world simultaneously and (Görke et al. 2017) (2) it is more sustainable. It reduces the number of materials needed, decreases the organizational effort in preparation and realization of the simulation, as well as the time required to carry out the event.

\section{RESEARCH GAP AND OBJECTIVE}

The digital simulations that exist today are mainly parametric models used to illustrate a real situation (Alves and Tommelein 2004; Carvalho et al. 2014; Abbasian-Hosseini et al. 2014). These models deliver the possibility to experiment with different variables of the system and to observe the effects created in function of different combinations of them (Rybkowski et al. 2008; Gadre et al. 2011).

There is a significant shortage of simulations run on a digital platform where interaction between participants is allowed in real-time. In current simulations, participants only interact with the platform or model of the system. Thus, social competencies cannot be developed. (Görke et al. 2017) Only one example of digital simulation for Lean principles with interaction between participants has been found in the literature (Kuriger et al. 2010). However, none has been found that instructs methods or tools of Lean Construction. The goal of this work is to adapt and create a Lean Construction simulation that can be run on a digital online platform, which allows realtime interactions between participants on a cloud-based game. 
As a digital Lean Construction simulation has not been developed before, the first step is to develop a digital simulation for teaching general Lean principles. Best practices of user experience (UX) design were implemented (Gualtieri, M. 2009). By doing this, the objective of this first step is to test the technical, logistical, and pedagogical aspects of this new virtual approach in a controlled environment. Once these aspects are validated, the second step is to develop a Lean Construction simulation which involves more creative facets. The method chosen to for this cause is the Last Planner® System (LPS). This methodology was developed by Glenn Ballard (Ballard, 2000) and is based on Lean principles. It is mainly used for production planning and control in the construction and real estate industry.

\section{ADVANTAGES OF DIGITAL SIMULATIONS}

Physical simulations enable active and independent decision making (Gadre et al. 2011; Heyl 2015). Through visual representation of processes and metrics they allow to learn about consequences of decisions and strategies (Shannon et al. 2010). This facilitates an experiential learning of Lean principles in error-friendly, dynamic learning environments.

Digital simulations offer an added value: they are more flexible than physical simulations in terms of time, space, and number of participants (Görke et al. 2017), reducing efforts in setting up and clearing away the elements needed in the simulation (Kuriger et al. 2010) as well as reducing the costs (Abbasian-Hosseini et al. 2014).

Digital simulations are not a completely different concept compared to physical simulations, but rather an extension of them. As shown in Figure 1, the characteristics of the physical simulations will be the foundations for the development of the digital simulations. Following this premise, the simulations are designed in this work.

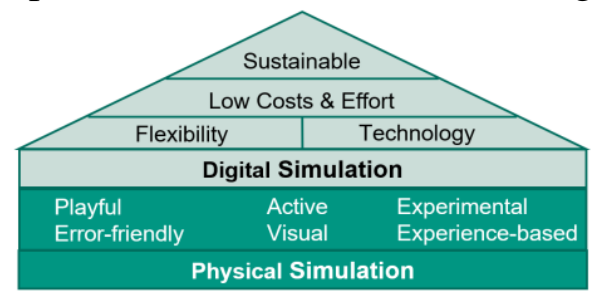

Figure 1: Advantages \& enhancement through digital simulations

Concretely, the simulations are designed focusing on the following objectives: (1) to engage all participants through attracting design, providing them a social and multimedia experience (Görke et al. 2017); (2) to meet appropriate difficulty levels that range between comfort zone and the participants' willingness to compete (Vin et al. 2018) and (3) to fulfil learning goals of physical simulations such as to be instructive, fun to perform, realistic, easy to play, intuitive in applying principles and to be inspiring in terms of application in practice (Kuriger et al. 2010). The second and third objective are closely related to gamification aspects (Azmi et al. 2015): By using game mechanics such as a feedback board, virtual goods, a progress bar; game dynamics such as transparent achievements and competition; and game aesthetics such as challenges; gamification elements can be implemented.

\section{REQUIREMENTS FOR A DIGITAL SIMULATION}

In order to develop a digital learning simulation, certain requirements must be considered regarding the simulation itself, the participants as well as the moderator (Tommelein et al. 1999). 


\section{Simulation Requirements}

Each simulation should be adapted to its participants (Vin et al. 2018). Regarding digital simulations, the participants' technological knowledge and their access to devices must be considered. To create an easy access to the software, even if the technological knowledge is low, a user-friendly design with clear instructions (Kuriger et al. 2010; Gadre et al. 2011) and graphics to visualize learning content (Kuriger et al. 2010) is very important. Also, the software should be compatible with the operative system of the participants. Additional devices like a mouse or a headset should be available for each participant. Duration of digital simulations is relevant since the attention span is clearly shorter and distractions by further applications on computers are possible (Kuriger et al. 2010). Lastly, according to Shannon et al. (2010), many digital simulations lack reference to reality. Therefore, a strong attention should be paid to this aspect.

\section{Participants Requirements}

Despite the emerging flexibility of a digital simulation, all participants must perform the simulation at the same time, regardless of different time zones. This time has to be blocked in all calendars of the participants (Kuriger et al. 2010).

A poor internet connection and the lack of personal contact can have a negative impact on the execution of the simulation. For this reason, participants must be encouraged to actively participate in the simulation. Their feedback should be collected and commented. A frequent shift of a practical, a feedback and a theory part has to be considered.

\section{Moderator Requirements}

Simulations should be led by a moderator in order to include all the relevant roles of a Lean Construction project. This person acts as a coach or trainer and not as a teacher (Leming-Lee et al. 2017). Besides the theoretical and practical knowledge of the simulations' objectives, the moderator should be further familiar with the software and should know how changes are made in the simulation (Shannon et al. 2010).

\section{METHODOLOGY FOR THE DEVELOPMENT}

The simulation is developed based on best practices of UX design (Gualtieri, M. 2009): Needs of the users were empathized. First, the simulation was designed, then tested internally and later with users. Finally, their feedback was implemented. This iterative procedure based on the PDCA cycle (planning, doing, control and acting) (Liker 2003) was run several times, resulting in user-oriented best practices.

In detail, as a first run, a simulation concept based on literature research was created. In the following runs, improvements were included as a basis for planning and goals were possibly adjusted. These were tested during the simulation and subsequently reviewed. In particular, a semi-standardized feedback questionnaire was distributed after two runs to its randomly assigned groups of participants. In this, they were able to evaluate the simulation on basis of individual factors such as fun and learning effect created by user interactions and game mechanics (Azmi et al. 2015). This questionnaire also allowed users to provide comments for further improvements. Using this approach, in total three runs or PDCA cycles were conducted for each of the two simulations. The first run served to check the technical requirements, the second run to test the teaching method of the didactic triangle (Tommelein et al. 1999) and the third run to check the learning success based on the objectives. The didactic triangle tests the relationship between moderator, participants, and simulation. 
These runs were conducted with different groups of experts. A group of Lean experts who had already gained experience with Lean simulations participated in the first and second runs. This allowed the didactic teaching method and the underlying theory to be verified. The third run was carried out with students in the master program without a corresponding basic knowledge. This target group represents the typical group of participants in the simulation.

\section{GUIDING A DIGITAL SIMULATION}

The first technical tests resulted in the decision to use Miro as software for the execution of the simulations. Miro is an online visual collaboration platform for teamwork, which made it suitable for generating the necessary virtual collaboration environment. Through the online whiteboard the processes are visually represented and can be used by several users simultaneously. The whiteboards can be shared through links with the users.

\section{Lean Principles Simulation}

The first simulation performed was on Lean principles. This is the typical simulation flow found in the literature: perform multiple rounds of incremental implementation of the Lean Principles and record metrics to track improvements and compare between rounds. The final version of the simulation has 5 stations (see Figure 2) and a duration of one hour and thirty minutes. The objective of the simulation is to create a product through the 5 production stations.

\begin{tabular}{ccccc}
\hline Station 1 & Station 2 & Station 3 & Station 4 & Station 5 \\
\hline$\rightarrow$ & $\rightarrow \square$ & $\square \rightarrow \mathrm{B}$ & $\mathrm{a} \rightarrow-$ & \\
\hline
\end{tabular}

Figure 2: Lean Principles Simulation - Production flow

To achieve this, participants must play the roles of the customer, a logistician, a general manager, time managers and quality managers. Role distribution can be combined as desired. The simulation needs at least 7 participants scaling to more than 14 people. The layout of the simulation in Miro is an aerial view of a factory (see Figure 3 and scan the QR-Code to watch a short teaser). It has a production room, a warehouse, and a Big Room. It includes a visual diagram of the production flow, production performance indicators and a table to record the stress of the participants in each round. There is also an area to visualize the Lean principles applied per round. This helps to understand the impact of the application of Lean principles on the improvement of the production process.

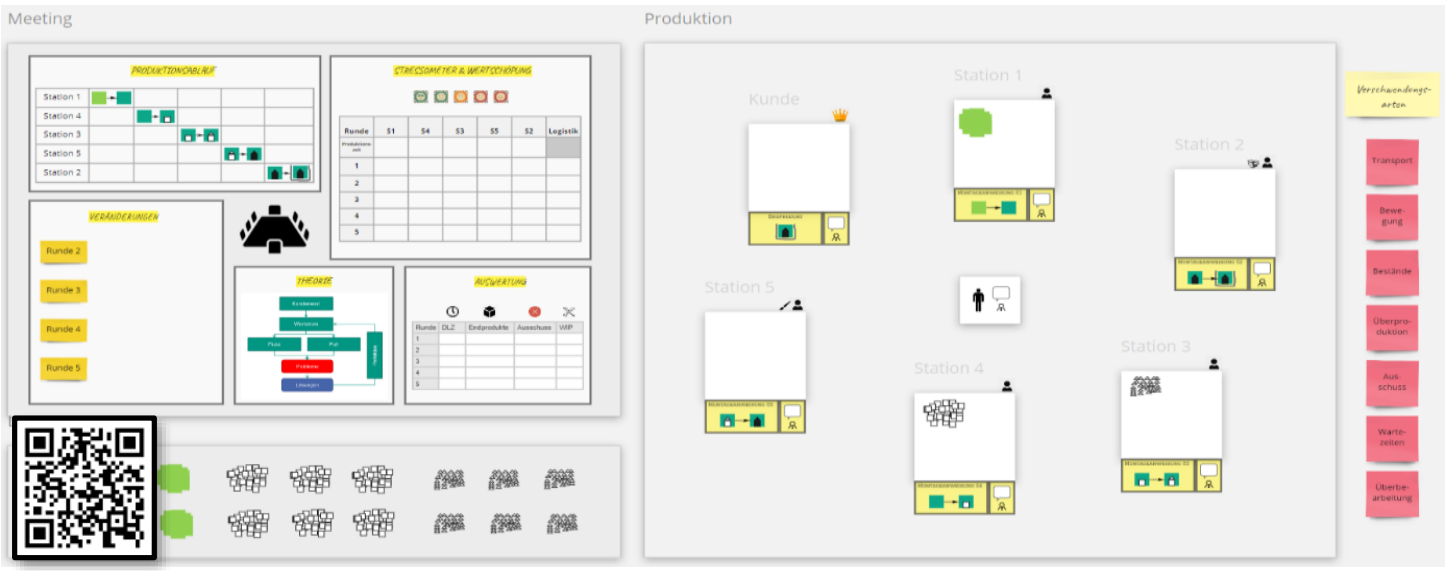

Figure 3: Lean Principles Simulation - Layout 


\section{Preparation for Playing the Simulation}

The simulation starts with a short introductory presentation run by the moderator, in which the participants are taught about technical aspects, such as recommended internet browser for the simulation and the use of mouse as main interface. Basic definitions necessary for the simulation are presented. An overview of the simulation layout is shown, explaining the production flow, the roles, the general simulation rules, and the definition of waste. After that, the participants are invited to enter the virtual environment in Miro. Inside the platform a technical introduction on the Miro functionalities is given. At this point, an overview of the layout is carried out "on site", and the role distribution is made by asking the participants to place the mouse cursors to desired roles.

\section{Test Run}

Each station processes three products and the logistician transports the produced parts. Time managers measure average production time of the respective stations and document it (see Figure 3). This test run serves to get an overview of the workload of the individual stations. Later harmonization in each one of the stations is introduced as a Lean principle. This test help to check whether participants have understood their role or if they have technical problems with the tool. After finishing the test run, all materials on stations are eliminated and the moderator place new material.

\section{Production Rounds}

The simulation starts when the moderator runs the stopwatch implemented in Miro for all to see. Each of the 5 rounds lasts 3 minutes and the objective of each round is to produce as many products as possible. After each round the participants organize a continuous improvement meeting, where each station and the logistician report their stress level. The general manager records key figures such as lead time, number of manufactured products, defective parts (detected by the quality managers) or rejected products (by the costumer) and the work-in-progress parts (in stations). In the final part of the meeting, the moderator leads the discussion stimulating the identification of waste of the respective round. Then, he gives a theory input about the Lean principles which can avoid the identified waste to discuss with the participants possible process improvements to be implemented (see

Table 1).

Table 1: Lean Principles Simulation - Sequence of rounds

\begin{tabular}{cccccc}
\hline After round... & $\mathbf{1}$ & $\mathbf{2}$ & $\mathbf{3}$ & $\mathbf{4}$ & $\mathbf{5}$ \\
\hline Type of Waste & $\begin{array}{c}\text { Transport, } \\
\text { Movement }\end{array}$ & $\begin{array}{c}\text { Inventory, } \\
\text { overproduction }\end{array}$ & $\begin{array}{c}\text { Defects, } \\
\text { Transport } \\
\text { One-piece- } \\
\text { flow }\end{array}$ & Waiting Time & $\begin{array}{c}\text { Over- } \\
\text { processing }\end{array}$ \\
$\begin{array}{c}\text { Improvement } \\
\text { applied }\end{array}$ & $\begin{array}{c}\text { Production } \\
\text { Line or }\end{array}$ & $\begin{array}{c}\text { Parts collection } \\
\text { from previous } \\
\text { station }\end{array}$ & $\begin{array}{c}\text { Batch size } \\
1\end{array}$ & $\begin{array}{c}\text { Elimination of } \\
\text { bottlenecks }\end{array}$ & Kaizen \\
\hline
\end{tabular}

\section{Closure and findings}

At the end of the event a survey was carried out to capture feedback from participants and test the knowledge acquired by them during the simulation.

The final version of the simulation was tested with 46 Lean Construction students divided into four groups. It lasted an hour and a half. All improvement suggestions were considered. Some opted for an in-line and others for a U-shaped layout of the stations; at the stations they defined separate areas for finished products and for products under construction. As a result, in the last round they applied the one-piece flow principle (reduction to lot size 1) and harmonization of the workload per station. 


\section{LAST Planner ${ }^{\circledR}$ System (LPS) Simulation}

The second simulation was designed to teach the LPS. It was based on a typical simulation process from literature research: execution of two rounds, one "conventional construction round" and a second round applying LPS. The simulation describes the construction process of the shell of a house (see Figure 4).

\begin{tabular}{|c|c|c|c|c|}
\hline Empty Land & Excavation & Pipes install & Reinforcement I & Foundation I \\
\hline . .0 & & & 事 & 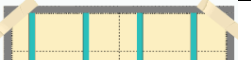 \\
\hline$\cdot{ }^{\circ} \cdot$ & & & & \\
\hline$\because \div$ & & & & \\
\hline $0^{\circ} \cdot{ }^{\circ}$ & & & Intre & th \\
\hline$\overline{\text { Reinforcement II }}$ & Foundation II & Exterior walls & Flooring & Interior walls (opt) \\
\hline 珊册册册 & & & & \\
\hline ' & & & & \\
\hline
\end{tabular}

Figure 4: LPS Simulation - Construction process

Each process step (see Figure 4) is simulated by a role. The role distribution is flexible and can be combined as desired (e.g.: two roles can be played by one person). The simulation needs at least 6 participants scaling up to 15 people. Further roles not shown in Figure 4 are construction manager, quality manager and construction logistics.

The layout of the simulation is again an aerial view of a construction site (see Figure 5 and scan the QR-Code to watch a short teaser). It has a construction area, two warehouses, one set of supplier materials per round and a Big Room. In this room there is a visual diagram of the construction process, tables with LPS elements such as a collaborative planning board and performance charts with the percentage of plan completed (PPC) or the stress of the workers per round. At the bottom of the layout, there is a group of videos presenting the construction process of each trade. This emulates the insight effect of viewing a construction process in a BIM model, helping participants to get a better understanding.

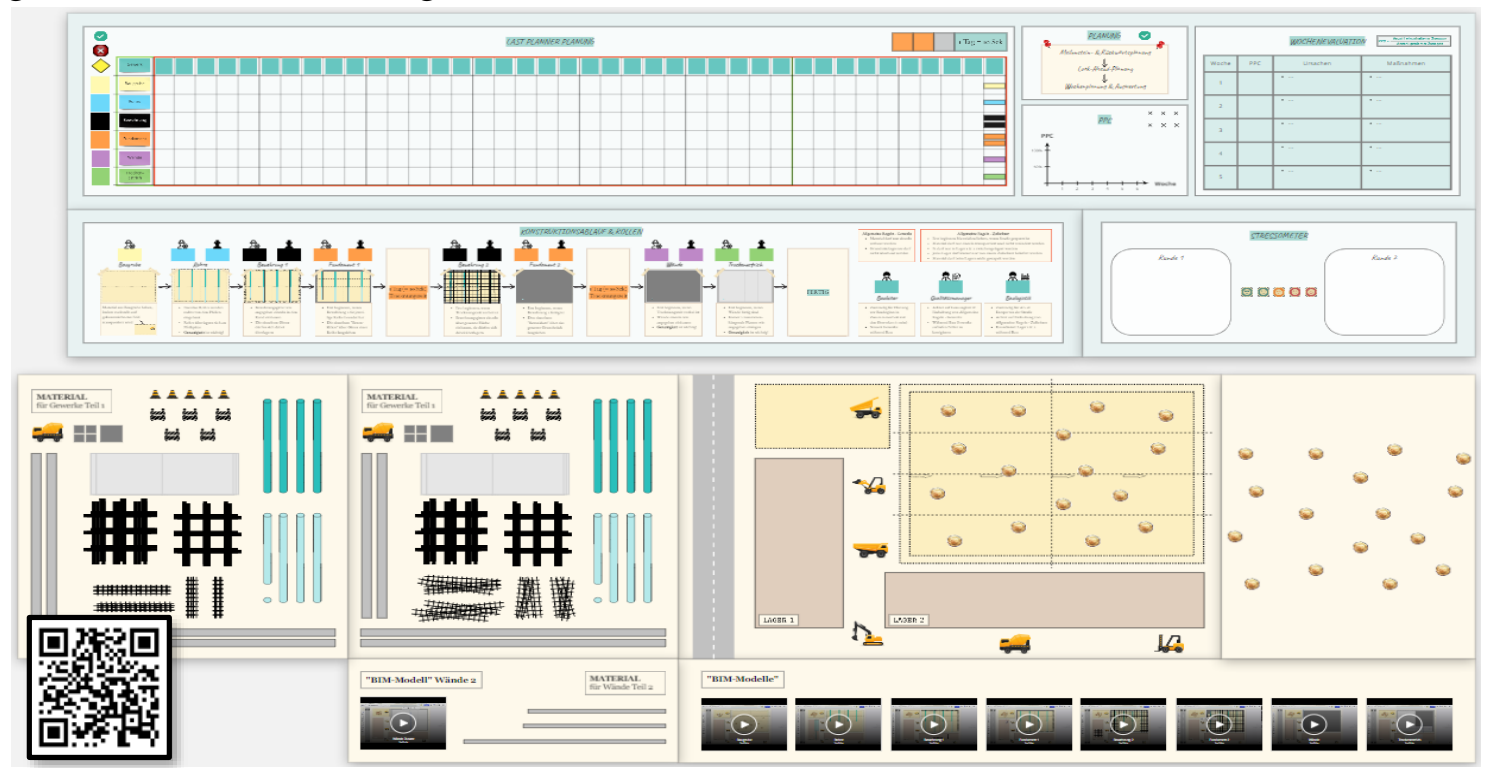

Figure 5: LPS Simulation - Layout 


\section{Preparation for Playing the Simulation}

The simulation introduction and rule explanation take place directly on Miro. During this phase, all frames in Miro remain hidden. The frames are unlocked progressively according to the stage of the simulation. This avoids overloading the participants with too many elements. The construction site is shown, tasks are explained, and roles are distributed. Participants are told that the goal of the game is to complete the construction within 6 weeks (corresponding to 5 minutes).

\section{Conventional Construction Round}

The site manager is given 1 minute to organize all the trades. After this, the simulation begins when the moderator starts the stopwatch. In this first round, time is allowed to run freely until the construction is completed. When the participants finish, the moderator records the time and points out deficiencies, integrating the participants into the discussion. In addition, participants report their stress level.

\section{Last Planner® System Rounds}

Before the second round starts, the moderator gives an overview about the phases of the collaborative LPS planning. Backward planning takes place interactively with all trades, in which they define task durations ( 1 day $=10$ seconds). When the plan is ready, the whole construction process plan is moved forward, and trades set milestones. Then, the look-ahead planning is carried out. The moderator engages the team to identify restrictions and to try solving them in advance. Each trade defines its tasks and sets commitments by pasting a digital sticky note in each committed day.

Building materials for the incoming week are provided and the second round starts with weekly interruptions (e.g., moderator says that the construction must be paused 10 seconds because of bad weather conditions): a week of 5 days is assumed, so the moderator stops the time count after 50 seconds, using a visible stopwatch.

At the end of the week the evaluation is moderated by the construction manager who fills the LPS board. Commitments and milestones are checked and depending on their completeness they are coloured red (incomplete) or green (complete) to visualize them. PPC is calculated and the causes of non-compliance are documented, as well as the measures to avoid them. The moderator supports the construction manager to involve all trades in the discussion. Special events can be introduced, these can be visualization of the construction process in a BIM model (showing a video of the process), rainy weather (stop activities for 10 seconds) and costumer request (installation of interior walls). After the last round, the moderator makes a final assessment of the project, and the stress level of the second round is filled out.

\section{Closure and Findings}

A survey was carried out at the end of the game as well. The final version of the simulation was tested with 32 Lean Construction students divided into two groups. It lasted an hour and a half. In the first conventional construction round both groups finished the construction in approximately 10 minutes and in the second round using the LPS the construction was finished in less than 5 minutes. PPC increased in the simulated weeks up to $100 \%$. To include special events, 120 minutes should be planned.

\section{EMPIRICAL ASSESSMENT}

To evaluate the developed digital simulations, feedback was collected from the participants through questionnaires with a 1-5 Likert scale and open questions. The total number of participants for each simulation and those who took part in filling out the 
questionnaires can be found in Table 2. It shows the average scores obtained by both simulations in the categories of design, fun, and moderation. Design was rated higher in the LPS Simulation while fun and the moderation had a higher score in the Lean Principles Simulation.

It can be noted that all rating results are in the upper range between 4 and 5 . The percentage of the technology represents the fulfilment of the technical requirements. In the LPS simulation $80 \%$ of the participants did not experience any technical problems. The fewer technical problems are reasoned since in the LPS simulation it was not necessary to mark and move multiple elements inside the Miro platform.

Table 2: Validation Digital Simulations - 1-5 Likert Scale from 1 (very low) to 5 (very high), Technology from $1 \%$ to $100 \%$ of Participants Questionnaire

\begin{tabular}{ccccccc}
\hline & $\begin{array}{c}\text { Simulation } \\
\text { Participants }\end{array}$ & $\begin{array}{c}\text { Assessment } \\
\text { Participants }\end{array}$ & Design & Fun & Moderation & Technology \\
\hline Lean Principles Simulation & 57 & 43 & 4.37 & 4.48 & 4.59 & $70 \%$ \\
LPS Simulation & 48 & 35 & 4.49 & 4.35 & 4.22 & $80 \%$ \\
\hline
\end{tabular}

Furthermore, the closeness to reality was measured by the participants rating the Lean Construction Simulation on a scale from 1 (hardly realistic) to 5 (very realistic). This resulted in an average value of 3.62. The freedom of decision was rated by the participants from a scale of 1 (very restricted) to 5 (very free) with an average of 3.97.

\section{CONCLUSION AND OUTLOOK}

As the results of the survey show, the research objectives defined at the beginning were achieved: The evaluation of the technology, the fun and the design indicate that the participants can successfully interact in real-time with each other via the chosen digital platform. Furthermore, the learning effect was achieved with the learning method: the participants move out of their comfort zone, are willing to get involved in the simulation and thus achieve the "aha" moment by anchoring the theory. Overall, not only were the advantages of a physical learning simulation achieved, but additional advantages of a digital simulation were included: Digital simulations offer high flexibility, integration of technology with low costs and effort as well as a high level of sustainability (see Figure 1). To support building relationships and commitment also in digital simulations, additional technologies such as Augmented Reality or Virtual Reality can be a future focus of research.

It has been shown with the implementation of the simulation that especially the freedom of decision of the participants has to be considered by the moderator. Here, especially through the digital format, the ratio between freedom (for the purpose of participants' development) and the structure given by templates and instructions must be considered. The degree of freedom can be analysed more in further runs of the simulation to find the perfect balance in between. Also, the chosen methodology and technique has proven itself, so that it can be transferred to other methods and tools. Thus, a first concept for a digital simulation for Takt planning and Takt control has already been developed.

\section{REFERENCES}

Abbasian-Hosseini, S.A., Nikakhtar, A., and Ghoddousi P. (2014). "Verification of Lean construction benefits through simulation modeling: A case study of bricklaying process." KSCE Journal of Civil Engineering, 18(5) 1248-1250.

Alves, T., and Tommelein, I. D. (2004). "Simulation of Buffering and Batching Practices in the Interface Detailing-Fabrication-Installation of HVAC Ductwork." 
Azmi, S., Iahad, N. A., \& Ahmad, N. (2015). "Gamification in online collaborative learning for programming courses: A literature review." ARPN Journal of Engineering and Applied Sciences, 10(23), 1-3.

Ballard, H. G. (2000). "The last planner system of production control." Doctoral dissertation, University of Birmingham.

Carvalho, C. V. de, Lopes, M. P., and Ramos, A. G. (2014). "Lean games approachesSimulation games and digital serious games." iJAC, 7(1) 14.

Cerveró-Romero, F., Napolitano, P., Reyes, E., and Teran, L. (2013, July). "Last Planner System ${ }^{\circledR}$ and Lean approach process ${ }^{\circledR}$ : experiences from implementation in Mexico." Proceeding IGLC-21, 709-718.

Dallasega, P., Revolti, A., Sauer, P. C., Schulze, F., and Rauch, E. (2020). "BIM, Augmented and Virtual Reality empowering Lean Construction Management: a project simulation game." Procedia Manufacturing, 45, 50.

Gadre, A., Cudney, E., and Corns, S. (2011). "Model development of a virtual learning environment to enhance Lean education." Procedia Computer Science, 6, 100.

González, V. A., Senior, B., Orozco, F., Alarcón, L. F., and Ingle, J., Best, A. (2014). "Simulation Lean production principle in construction: A last planner-driven game." Proceeding IGLC-22, Oslo, Norway.

Görke, M., Bellmann, V., Busch, J., and Nyhuis, P. (2017). "Employee qualification by digital learning games." Procedia Manufacturing, 9, 231, 235.

Gualtieri, M. (2009). "Best practices in user experience (UX) design." Design Compelling User Experiences to Wow your Customers, 1-17.

Herrera, R. F., Sanz, M. A., Montalbán-Domingo, L., García-Segura, T., and Pellicer, E. (2019). "Impact of game-based learning on understanding Lean construction principles.” Sustainability, 11(19) 5294.

Heyl, J. von (2015, July). "Lean simulation in road construction: teaching of basic Lean principals." Proceedings IGLC-23. Perth. Australia, 406.

Kriz, W. C. (2003). "Creating effective learning environments and learning organizations through gaming simulation design." Simulation \& Gaming, 34(4), 504.

Kuriger, G. W., Wan, H. D., Mirehei, S. M., Tamma, S., and Chen, F. F. (2010). "A webbased Lean simulation game for office operations: training the other side of a Lean enterprise." Simulation \& Gaming, 41(4) 488-489, 500-503.

Leming-Lee, S., Crutcher, T. D., \& Kennedy, B. B. (2017). "The Lean methodology course: Transformational learning." The Journal for Nurse Prac., 13(9) 420.

Liker, J. (2004). "The Toyota way. 14 management principles from the world's greatest manufacturer." New York, NY: McGraw-Hill, 350 pp.

Rybkowski, Z. K., Wong, J. M., Ballard, G., and Tommelein, I. D. (2008). "Using controlled experiments to calibrate computer models: the Airplane Game as a Lean simulation exercise." Proceedings IGLC-16, 315.

Shannon, P. W., Krumwiede, K. R., and Street, J. N. (2010). "Using simulation to explore Lean manufacturing implementation strategies." Journal of Management Education, 34(2) 287, 290.

Tommelein, I.D., Riley, D., and Howell, G.A. (1999). "Parade Game: Impact of Workflow Variability on Trade Performance." J. Constr. Eng. Manage., 125(5) 304-310.

Vin, L. de, Jacobsson, L., and Odhe, J. (2018). "Game-based Lean production training of university students and industrial employees.” Procedia Manufacturing, 25, 579. 